\title{
CURRÍCULOS DE SECRETARIADO EXECUTIVO: ALGUMAS REFLEXÕES
}

\section{CURRICULUM OF EXECUTIVE SECRETARIAT: SOME REFLECTIONS}

\section{Ubirajara Junior Gerardin}

Especialista em Docência para o Ensino Superior pelo Centro Universitário Hermínio Ometto - UNIARARAS

ubirajara.gerardin@terra.com.br

\section{Aneridis Aparecida Monteiro}

Doutora em Educação pela Pontifícia Universidade Católica de São Paulo -PUC/SP Coordenadora do Curso Licenciatura em Pedagogia do Centro Universitário Herminio Ometto de Araras - UNIARARAS

aneridismonteiro@uniararas.br

\section{Viviana Cristina Giani}

Especialista em Educação pelo Centro Universitário Claretiano de Batatais viviana@claretianas.br 


\section{RESUMO}

Ao longo dos últimos anos o curso de graduação em bacharelado em Secretariado Executivo é alvo de concepções errôneas, bem como de comparações equivocadas a outros cursos de áreas afins e/ou nomenclaturas semelhantes. Emerge nesse sentido a necessidade de estudos que tragam de forma esclarecedora, a discussão de como é elaborada a estrutura curricular desse curso de graduação. Dessa forma, neste artigo tem como objetivo principal comparar a estrutura curricular de três instituições de ensino superior do Brasil, tendo como objeto de estudo duas universidades públicas e uma privada em três regimes distintos, federal, estadual e privado. Para tanto, parte-se de um levantamento bibliográfico com autores que têm discutido as concepções de currículo, de um modo geral, servindo como base no estudo, bem como à abordagem da Diretriz Curricular Nacional (DCN) do curso no intuito de verificar os aspectos igualitários e diferenciais em relação a estas três instituições de ensino superior, onde foram valorizadas esferas de ordem social, institucional e regimentar. As conclusões apontam para a abrangência e relevância do curso de Secretariado Executivo, bem como que as Instituições de Ensino Superior (IES) analisadas estão adequadas às exigências do Ministério da Educação no tocante à formação acadêmica desses profissionais.

Palavras-chave: Currículo; Educação; Secretariado Executivo. 


\section{ABSTRACT}

Along the last years, it is noticed that the degree course in baccalaureate in Executive Secretariat is white of erroneous conceptions, as well as of mistaken comparisons the other courses of similar areas and/or similar nomenclatures. It emerges in that sense the need of studies that you/they swallow in an explanatory way, the discussion of as the curriculum structure of that degree course is elaborated. In that way, this article has as main objective to compare the curriculum structure of three institutions of higher education of Brazil, tends as object of study two public universities and a toilet in three regimes different, federal, state and matter. For so much, it breaks of a bibliographical rising with authors that have been discussing the curriculum conceptions, in general, serving as base in the study, as well as to the approach of the Guideline National Curriculum (DCN) of the course in the intention of verifying the equalitarian and differential aspects in relation to these three higher education institutions, where spheres of order social, institutional and regimental will be valued. The conclusions appear for the inclusion and relevance of the course of Executive Secretariat, as well as that analyzed IES are adapted to the demands of Ministry of Education concerning those professionals' academic formation.

Keywords: Curriculum; Education; Executive Secretariat. 


\section{INTRODUÇÃO}

As instituições de ensino superior necessitam estar atentas às questões curriculares que envolvem a formação do profissional de secretariado executivo, devido ao crescimento da dimensão profissional deste.

Bíscoli e Cielo (2004) reforçam essa questão apontando que os aspectos da formação devem recair sobre a compreensão do profissional a despeito da organização em que atua com a visão holística, desempenhando suas funções essenciais, mas também analisando os desdobramentos de cada uma delas. Assim, pode-se observar a importância e a relevância do campo, utilidade, bem como da finalidade do currículo para uma formação consistente em âmbito superior. Para Macedo (2009), o currículo assume papel de extrema importância, universalmente falando, tendo em vista que o mesmo traduz a concepção e a construção contemporânea das formações.

Nesse sentido, o desconhecimento e/ou a falta de orientação sobre o campo, utilidade e a finalidade do currículo do curso de Secretariado Executivo, gera um conflito de concepções sobre essa formação, bem como sobre o curso universitário de um modo geral. Assim, emerge a necessidade da análise e reflexão da proposta curricular do curso que recai sobre a formação do profissional de secretariado executivo, no intuito de esclarecer e diminuir as concepções errôneas dessa área.

Desta forma, no presente artigo versa sobre dois objetivos: analisar as concepções do currículo de um modo geral, bem como as singularidades do currículo do curso de graduação em Secretariado Executivo e discorrer também sobre essa área, no intuito de evidenciar aos demais a relevância e a importância da formação universitária frente às necessidades e exigências do mercado de trabalho. Em uma primeira instância o trabalho resgata os conceitos gerais de currículo, abordando questões referentes ao seu campo, conceito, pesquisa e utilidade. Num segundo momento aborda especificamente o curso de graduação em Secretariado Executivo, levantando elementos importantes de sua proposta curricular (formação acadêmica), bem como de suas peculiaridades frente às exigências do mercado de trabalho para uma boa atuação profissional. 


\section{CURRÍCULO: CAMPO, CONCEITO E PESQUISA}

Aqui se justifica o título Currículo: campo, conceito e pesquisa, devido o trabalho de Macedo (2009) em seu livro com o mesmo título, uma vez que ele reflete fidedignamente o delinear das discussões acerca do Currículo.

Nesse sentido, Macedo (2009) destaca que não se deve reduzir a concepção de currículo como mero processo de mercadorização, nem tampouco inferiorizá-lo com concepções diminutivas que o limite às questões cotidianas. 0 autor ainda destaca que:

[...] cai nas concepções delirantes de quem acha que as coisas da educação não têm especificidade e que toda fonte de elucidação e debate é válida para compreender 0 ato educativo a partir, apenas, da sua própria lógica ou linguagem. (MACEDO, 2009, p. 18)

Em acréscimo a ensinança de Macedo (2009), Garcia e Moreira (2003) discorrem que as teorizações acerca do currículo se distanciam da real discussão sobre o campo do mesmo. Comentam que essas referidas teorizações não estão dando conta de explicar, bem como enriquecer o campo do currículo e seu papel no que se refere às instituições de ensino (escola).

Partindo de uma análise mais pessoal, Costa (2005) comenta que o currículo escolar caracteriza um dos agentes que constituem o caminho que torna as pessoas no que são.

Pode-se refletir então, que o currículo se universaliza de um modo mais amplo e complexo, o qual vai além de especulações ou concepções do senso comum e que muitas dessas errôneas especulações acabam por prejudicar o campo teórico desse assunto.

Partindo desse pressuposto, emerge-se a necessidade do estudo do currículo de graduação do curso de Secretariado Executivo, no intuito de agir como auxílio da tentativa de assegurar uma formação consistente e verdadeira dentro dos moldes dessa área. 


\title{
3 O CURSO DE GRADUAÇÃO EM SECRETARIADO EXECUTIVO: ALGUMAS REFLEXÕES
}

Muito vem sendo discutido no campo de Secretariado Executivo. Atualmente as discussões perpassam o simples fato especulativo dessa área de formação e tampouco se limitam às questões de perfil profissional.

Porém, ainda se encontram dificuldades em quebrar o paradigma de que o curso universitário possui somente visão e formação tecnicista, bem como resistência em se fortalecer enquanto área do conhecimento humano.

A Resolução no. 3, em seu artigo 30, parágrafo único, aponta a consistência do curso de Secretariado Executivo, a saber:

\begin{abstract}
O bacharel em Secretariado Executivo deve apresentar sólida formação geral e humanística, com capacidade de análise, interpretação e articulação de conceitos e realidades inerentes à administração pública e privada, ser apto para o domínio em outros ramos do saber, desenvolvendo postura reflexiva e crítica que fomente a capacidade de gerir e administrar processos e pessoas, com observância dos níveis graduais de tomada de decisão, bem como capaz para atuar nos níveis de comportamento microorganizacional, mesoorganizacional e macroorganizacional. (BRASIL, 2005, p. 2).
\end{abstract}

Nesse sentido, pode-se notar a relevância do profissional de Secretariado Executivo, uma vez que ele assume papel de assessor frente às questões de alta relevância das organizações; por conseguinte, vale observar a importância de uma formação universitária consistente desse profissional.

Partindo desses apontamentos, pode-se dizer que o firmamento das questões que envolvem a especificidade e a abrangência do curso universitário, bem como a produção científica podem ser fatores que remetam à quebra desse paradigma.

Cabe ressaltar que o curso de graduação em Secretariado Executivo, com vistas à estruturação e fundamento de seu currículo tem a preocupação de provocar reflexões do profissional dessa área frente à diversidade que encontrará no mercado de trabalho. Assim, no que se refere à natureza do curso, pode-se destacar: "[...] o curso não somente procura uma nova tomada de posição teórica, mas também pretende transformar em ação concreta os resultados de seu trabalho. Procura conhecer para aplicar, para realizar uma tomada de decisão executória". (Hoeller apud Sabino e Marchelli, 2009, p. 612). 
Em consonância ao exposto, conforme Fávero e Durante (2009), pode-se pensar que a discussão do tema pode instigar os demais a conhecerem verdadeiramente a estrutura da graduação em Secretariado Executivo, provocando assim o repensar dessa área, demonstrando a importância da formação superior para o desempenho qualificado desta profissão.

Em decorrência disso, o currículo se faz presente neste aspecto, no intuito de tornar consistente as discussões do tema. Assim, de acordo com Macedo (2009):

[...] o lexema currículo, proveniente do étimo latino currere, significa caminho, jornada, trajetória, percurso a seguir e encerra, por isso, duas ideias principais: uma de sequência ordenada, outra de noção de totalidade de estudos. (PACHECO apud MACEDO, 2009, p. 22)

Nesse sentido o sistema educativo, de um modo geral, deve possibilitar meios para que o alunado desenvolva a capacidade de responder aos diversos problemas, bem como intervir na realidade que venha a enfrentar, uma vez que o objeto de estudo escolar pauta-se nos conhecimentos, nos conceitos, nas habilidades, nos procedimentos, nos valores e nas atitudes (ZABALA, 2005).

Vale lembrar que o currículo se universaliza de forma complexa e abrangente, porém para facilitar a compreensão ele é reduzido à abordagem da esfera do ementário do curso de graduação em Secretariado Executivo, bem como das Diretrizes Curriculares Nacionais estabelecidas pelo MEC.

Tendo em vista o cenário acentuado de desenvolvimento científico, bem como das grandes inovações de mercado, consequentemente as instituições de ensino superior adaptam sua estrutura curricular à dada realidade. Da mesma forma que os profissionais da área secretarial são exigidos a desempenhar suas funções e tarefas com maior competência.

\section{A FORMAÇÃO UNIVERSITÁRIA DO SECRETÁRIO EXECUTIVO}

O primeiro curso universitário de secretariado executivo surgiu no final da década de 1960 e início dos anos 1970 na Universidade Federal da Bahia; vê-se aqui que não é um curso tão novo, pois já possui suas raízes universitárias há quarenta anos.

Revista de Gestão e Secretariado, São Paulo, v. 2, n. 2, p.58-78, jul./dez. 2011. 
O Ministério da Educação homologou em 2/6/2003 e 12/4/2004, as Diretrizes Curriculares Nacionais do curso de Graduação em Secretariado Executivo (SANTOS e CAIMI, 2009). Essas diretrizes foram instituídas no intuito de nortear os veículos de formação dessa área profissional (ementas, projetos pedagógicos, entre outros).

As autoras auxiliam na compreensão do papel das Diretrizes Curriculares, bem como dos Projetos Pedagógicos; salientam que as Diretrizes versam sobre as linhas gerais a serem seguidas pelas IES, já os Projetos trabalham com as linhas específicas que vão ditar diretamente a questão da formação desse profissional.

Ainda partindo desse entendimento, as DCNs ditam o perfil do profissional de secretariado, o qual será delineado ao longo de sua formação acadêmica.

No tocante a área de Secretariado Executivo, Santos e Caimi (2009) relatam: "[...] capacidade e aptidão de compreensão das questões que envolvam sólidos domínios científicos, acadêmicos, tecnológicos e estratégicos [...]" (SANTOS e CAIMI, 2009, p. 30).

As Diretrizes Curriculares Nacionais também mencionam que a formação assegura ainda que o secretário executivo desempenhe múltiplas funções, levando-se em consideração as particularidades de cada organização, bem como o gerenciamento com sensibilidade, discrição e competência do fluxo de informações e comunicações internas e externas.

Ainda segundo as DCNs, artigo 40, incisos I ao XIII, o curso deve possibilitar a formação profissional que revele as seguintes competências e habilidades:

I - capacidade de articulação de acordo com os níveis de competências fixadas pelas organizações;

II - visão generalista da organização e das peculiares relações hierárquicas e intersetoriais;

III - exercício de funções gerenciais, com sólido domínio sobre planejamento, organização, controle e direção;

IV - utilização do raciocínio lógico, crítico e analítico, operando com valores e estabelecendo relações formais e causais entre fenômenos e situações organizacionais;

$\mathrm{V}$ - habilidade de lidar com modelos inovadores de gestão;

VI - domínio dos recursos de expressão e de comunicação compatíveis com o exercício profissional, inclusive nos processos de negociação e nas comunicações interpessoais ou intergrupais;

VII - receptividade e liderança para o trabalho em equipe, na busca da sinergia; 
VIII - adoção de meios alternativos relacionados com a melhoria da qualidade e da produtividade dos serviços, identificando necessidades e equacionando soluções;

IX - gerenciamento de informações, assegurando uniformidade e referencial para diferentes usuários;

$X$ - gestão e assessoria administrativa com base em objetivos e metas departamentais e empresariais;

XI - capacidade de maximização e otimização dos recursos tecnológicos;

XII - eficaz utilização de técnicas secretariais, com renovadas tecnologias, imprimindo segurança, credibilidade e fidelidade no fluxo de informações; e

XIII - iniciativa, criatividade, determinação, vontade de aprender, abertura às mudanças, consciência das implicações e responsabilidades éticas do seu exercício profissional. (BRASIL, 2005, pp. 2-3).

Um comentário interessante que deve ser ressaltado, de acordo com Santos e Caimi (2009), bem como com as determinações das DCNs, é que as IES relacionam as funções que o novo profissional desempenha no currículo, exigindo um trabalho interdepartamental e interdisciplinar, desde o aprendizado acadêmico.

Com isso, pode-se observar a amplitude da formação desse profissional, bem como da complexidade da mesma, tendo em vista que sua formação engloba fatores de ordem de domínios complexos, pois todos estão pautados na questão do pensar e do agir dentro de determinada realidade.

Bíscoli e Cielo (2004) reforçam esse ponto estimulando a concepção de novos domínios que devem estar presentes quando da formação do profissional secretário:

Com a evolução do perfil profissional, mudanças curriculares são estimuladas a fim de transformar os cursos superiores em formadores de profissionais que, além do cumprimento de rotinas secretariais como organização de eventos, arquivística e etiqueta profissional, sejam capazes de compreender a organização e suas atitudes (BÍSCOLI e CIELO, 2004, p. 1).

Não obstante, a formação do secretário executivo engloba fatores de ordem local, regional, nacional e universal, pois está previsto nas referidas diretrizes, uma formação abrangente e domínio de quatro conteúdos: científico, acadêmico, tecnológico e estratégico (SANTOS e CAIMI, 2009).

Contudo, cabe ressaltar que as DCNs não têm acompanhado a evolução do mercado, e, por conseguinte não acompanharam a evolução do perfil do secretário executivo exigido atualmente para o bom desempenho profissional, 
uma vez que a legislação pertinente, instituída pela Resolução no. 3 de 2005 não sofreu mais alterações desde sua data de homologação.

Nesse ponto faz-se menção a maior atribuição do profissional secretário, o fato de assessorar seus superiores (grifo nosso); as Diretrizes Curriculares Nacionais discorrem, implicitamente, este papel do currículo, objetivando a formação do secretário executivo.

Aqui é interessante ressaltar o debate teórico-metodológico da formação do Secretário Executivo, cujo ato, pós-formação é o de assessorar.

Para contribuir com esse conceito, Nonato Júnior (2009) faz menção às ciências da assessoria:

[...] as Ciências da Assessoria instauram-se a partir da complexidade dos conhecimentos produzidos e gerenciados pelos profissionais assessores, sobretudo no campo acadêmico, em que os cursos de Secretariado Executivo têm produzido vastos materiais em pesquisas sobre as questões aplicadas à profissão. (NONATO JÚNIOR, 2009, p. 42)

Desse modo, pode-se pensar que o campo do Secretariado Executivo possui uma raiz fomentada pela assessoria, intrinsecamente ligada ao seu Currículo. Porém, cabe frisar novamente que não ocorreram mais reformas curriculares desse patamar na área do secretariado. $O$ que se nota são reformulações da matriz curricular, propostas pelas próprias IES, no intuito de acompanhar a evolução/exigências advindas do mercado.

Assim, esse debate vem fomentar e instigar os pesquisadores e dirigentes a repensarem suas colocações acerca do curso de Secretariado Executivo, fazendo-os analisar com mais propriedade as propostas desse curso.

Retomando as questões pertinentes ao currículo, de um modo geral, é interessante destacar que o papel da universidade pauta-se no desenvolvimento do "tripé" da educação, o ensino, a pesquisa e a extensão.

Severino (2007) faz menção às três dimensões das universidades. No que se refere ao ensino, cita que a atividade ensino-aprendizagem está ligada diretamente à construção do conhecimento; a partir da pesquisa evidencia que esta é coextensiva, e que deve ser pautada em seu campo e objetivos, não perdendo de vista o fato de que seu maior objetivo é o de identificar os problemas relacionados à humanidade, bem como que os resultados de suas investigações tragam contribuições para ela. No que se refere à extensão, 
comenta que é o processo que articula o ensino e a pesquisa, criando um vínculo entre a universidade e a sociedade.

A partir desse entendimento, podemos refletir que todo e qualquer curso universitário tem sua formação assentada nesse "tripé", uma vez que em suas propostas curriculares ocorre a promoção e a formação de cidadãos conscientes, críticos e comprometidos com os problemas da sociedade. Desse modo, pode-se pensar que as universidades em geral têm essa preocupação, pois esse processo é intrínseco à sua filosofia.

Retomando o currículo e a formação do secretário executivo, observa-se que ele possui uma formação pluralista em diversas áreas do conhecimento, as quais o capacitam a atuar eficazmente e eficientemente frente à diversidade de um modo geral.

As concepções do currículo bem como a complexidade na formação do secretário executivo fazem refletir também sobre a complexidade de disciplinas e áreas do conhecimento que têm de capacitar este profissional a atuar no mercado de trabalho. Dessa forma, a preocupação das universidades é cumprir com as determinações das Diretrizes Curriculares Nacionais, bem como com os regimentos e estatutos legais ligados a essa área. E é nesse ponto que se analisa - currículo dos cursos de Secretariado Executivo das três universidades elencadas para o estudo, duas de regime público (federal e estadual) e outra de regime privado, no tocante às suas informações de ordem regimentar/institucional que recaem sobre a formação de seu alunado, a saber:

Chama-se Univ. I a Universidade de Regime Público-Federal. A referida universidade forma profissionais com a nomenclatura de Secretariado Executivo Trilíngue, pois desenvolve suas atividades abordando três idiomas: português, inglês e francês. Para integralização do curso, o acadêmico deve cumprir 2775 horas, as quais se pautam somente em disciplinas obrigatórias, sendo que outras 240 são direcionadas a disciplinas optativas, integralizando um total de 3015 horas. O mínimo período para formação é de três anos e meio, o período padrão de quatro anos, tendo como prazo máximo sete anos.

Chama-se Univ. II a Universidade de Regime Público-Estadual. A referida universidade forma profissionais com a nomenclatura de Secretariado Executivo Trilíngue, pois desenvolve suas atividades abordando três idiomas: português, inglês e espanhol. Para integralização do curso, o acadêmico deve cumprir 2802

Revista de Gestão e Secretariado, São Paulo, v. 2, n. 2, p.58-78, jul./dez. 2011. 
horas, as quais se pautam somente em disciplinas obrigatórias, sendo que 120 horas são desenvolvidas ao longo de atividades complementares. O período mínimo para integralização de créditos para formação é de quatro anos, tendo como prazo máximo sete anos.

Chama-se Univ. III a Universidade de Regime Privado. A referida universidade forma profissionais com a nomenclatura de Secretariado Executivo Trilíngue, pois também desenvolve suas atividades abordando três idiomas: português, inglês e espanhol. Para integralização do curso, o acadêmico deve cumprir 2440 horas, as quais se pautam somente em disciplinas obrigatórias, sendo que sessenta horas são desenvolvidas ao longo de atividades complementares. O período mínimo para integralização de créditos para formação é de três anos, tendo como prazo máximo cinco anos. A Instituição não trabalha com disciplinas optativas, sendo todas como regime obrigatório para conclusão do curso.

A partir desse momento apresenta-se a matriz curricular ipsis litteris, dos cursos das 3 IES pesquisadas, as quais depois de analisados os conteúdos, foram agrupadas de acordo o domínio que trabalham e com o que está previsto na Resolução no 3 de 2005 em seu artigo 30:

\begin{tabular}{|c|c|c|c|}
\hline \multicolumn{4}{|c|}{ Tabela 01 - Matriz de Universidade Federal (Univ. I) } \\
\hline Domínio Tecnológico & Domínio Estratégico & Domínio Científico & Domínio Acadêmico \\
\hline \multicolumn{4}{|c|}{ Disciplinas Obrigatórias } \\
\hline $\begin{array}{l}\text { Introdução à } \\
\text { Informática }\end{array}$ & $\begin{array}{l}\text { Teoria Geral da } \\
\text { Administração I }\end{array}$ & $\begin{array}{c}\text { Metodologia de } \\
\text { Pesquisa Aplicada ao } \\
\text { Secretariado } \\
\text { Executivo }\end{array}$ & Língua Inglesa I \\
\hline \multirow[t]{9}{*}{$\begin{array}{c}\text { Técnicas e } \\
\text { Tecnologia da } \\
\text { Comunicação Oral }\end{array}$} & $\begin{array}{c}\text { Instituições de } \\
\text { Direito }\end{array}$ & & Língua Francesa I \\
\hline & $\begin{array}{c}\text { Introdução ao } \\
\text { Secretariado } \\
\text { Executivo }\end{array}$ & & $\begin{array}{c}\text { Leitura e Produção } \\
\text { de Textos } \\
\text { Empresariais }\end{array}$ \\
\hline & $\begin{array}{l}\text { Introdução à } \\
\text { Economia }\end{array}$ & & Psicologia \\
\hline & Contabilidade Geral & & Língua Inglesa II \\
\hline & Arquivística; & & Língua Francesa II \\
\hline & $\begin{array}{c}\text { Organização, } \\
\text { Sistemas e Métodos }\end{array}$ & & Sociologia \\
\hline & Gestão Documental & & Língua Inglesa III \\
\hline & $\begin{array}{c}\text { Relações } \\
\text { Internacionais }\end{array}$ & & Língua Francesa III \\
\hline & $\begin{array}{l}\text { Assessoria Executiva } \\
\text { e Gestão Estratégica }\end{array}$ & & Redação Empresarial \\
\hline
\end{tabular}


Ubirajara Junior Gerardin, Aneridis Aparecida Monteiro \& Viviana Cristina Gianini

\begin{tabular}{|c|c|c|c|}
\hline & $\begin{array}{c}\text { Assessoria } \\
\text { Parlamentar e } \\
\text { Gestão Pública }\end{array}$ & & Língua Inglesa IV \\
\hline & $\begin{array}{c}\text { Gestão Secretarial e } \\
\text { Empreendedora }\end{array}$ & & Língua Francesa IV \\
\hline & & & Redação Oficial \\
\hline & & & Língua Espanhola I \\
\hline & & & Inglês Empresarial I \\
\hline & & & Francês Empresarial \\
\hline & & & $\begin{array}{l}\text { Língua Espanhola II } \\
\text { Inglês Fmprecarial }\end{array}$ \\
\hline & & & Língua Espanhola III \\
\hline & & & $\begin{array}{c}\text { Produção Escrita em } \\
\text { Língua Inglesa }\end{array}$ \\
\hline & & & $\begin{array}{l}\text { Comunicação Oral } \\
\text { em Língua Inglesa }\end{array}$ \\
\hline & & & $\begin{array}{c}\text { Espanhol } \\
\text { Empresarial }\end{array}$ \\
\hline $\begin{array}{c}\text { Estágio } \\
\text { Supervisionado }\end{array}$ & $\begin{array}{c}\text { Estágio } \\
\text { Supervisionado }\end{array}$ & $\begin{array}{c}\text { Estágio } \\
\text { Supervisionado }\end{array}$ & $\begin{array}{c}\text { Estágio } \\
\text { Supervisionado }\end{array}$ \\
\hline Domínio Tecnológico & Domínio Estratégico & Domínio Científico & Domínio Acadêmico \\
\hline & Disciplinas & Optativas & \\
\hline $\begin{array}{c}\text { Sistemas de } \\
\text { Informação Gerencial }\end{array}$ & $\begin{array}{c}\text { Teoria Geral da } \\
\text { Administração II }\end{array}$ & Monografia & Discurso Empresarial \\
\hline $\begin{array}{c}\text { Informática Aplicada } \\
\text { ao Secretariado } \\
\text { Executivo }\end{array}$ & $\begin{array}{l}\text { Matemática } \\
\text { Financeira }\end{array}$ & & Teoria Política \\
\hline & $\begin{array}{c}\text { Administração de } \\
\text { Recursos Humanos I }\end{array}$ & & Legislação Social \\
\hline & $\begin{array}{c}\text { Administração de } \\
\text { Recursos Humanos II }\end{array}$ & & $\begin{array}{c}\text { Direito } \\
\text { Administrativo }\end{array}$ \\
\hline & $\begin{array}{c}\text { Desenvolvimento } \\
\text { Organizacional }\end{array}$ & & Direito de Empresa \\
\hline & Análise de Custos I & & Economia Brasileira \\
\hline & $\begin{array}{c}\text { Estrutura e Análise } \\
\text { das Demonstrações } \\
\text { Financeiras }\end{array}$ & & Filosofia \\
\hline & Finanças Públicas & & Psicologia Social \\
\hline & Marketing I & & $\begin{array}{c}\text { Psicologia e } \\
\text { Administração }\end{array}$ \\
\hline & $\begin{array}{c}\text { Identificação e } \\
\text { Viabilização de } \\
\text { Oportunidades de } \\
\text { Negócios } \\
\end{array}$ & & $\begin{array}{c}\text { Sociologia do } \\
\text { Trabalho }\end{array}$ \\
\hline & $\begin{array}{c}\text { Sociologia Aplicada à } \\
\text { Administração }\end{array}$ & & $\begin{array}{c}\text { Comunicação } \\
\text { Organizacional }\end{array}$ \\
\hline & $\begin{array}{c}\text { Planejamento } \\
\text { Ergonômico do } \\
\text { Trabalho }\end{array}$ & & Geografia Cultural \\
\hline & Dinâmica de Grupo & & $\begin{array}{c}\text { Práticas de Revisão } \\
\text { de Textos }\end{array}$ \\
\hline & Marketing Pessoal; & & Língua Latina \\
\hline & $\begin{array}{c}\text { Tópicos Especiais em } \\
\text { Secretariado } \\
\text { Executivo I }\end{array}$ & & $\begin{array}{c}\text { Introdução à Cultura } \\
\text { Clássica }\end{array}$ \\
\hline
\end{tabular}

Revista de Gestão e Secretariado, São Paulo, v. 2, n. 2, p.58-78, jul./dez. 2011. 
Currículos de secretariado executivo: algumas reflexões

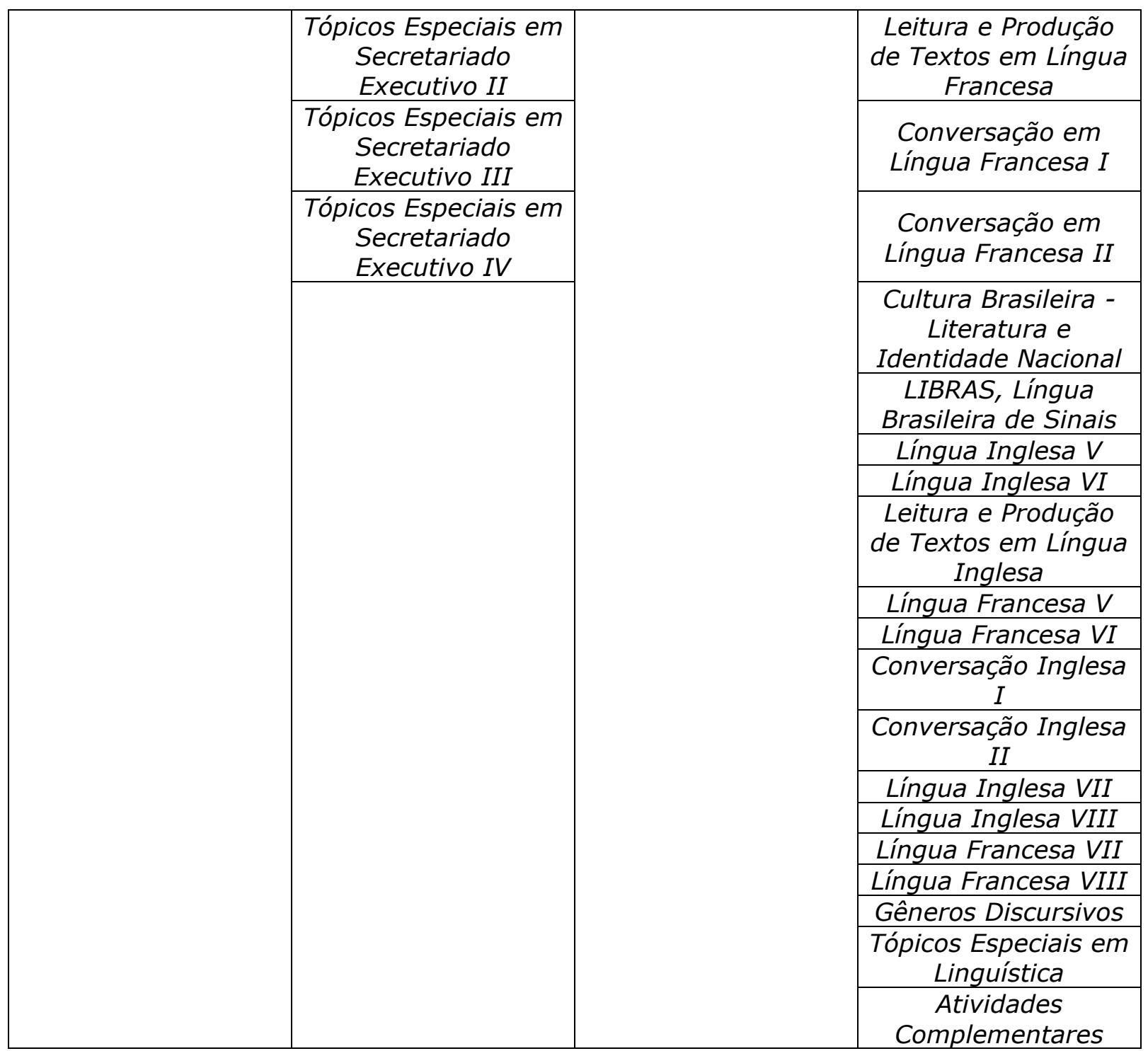

Fonte: Elaborado pelos autores, 2010.

Org.: Ubirajara Gerardin Júnior, Aneridis Aparecida Monteiro e Viviana Cristina Gianini.

\begin{tabular}{|c|c|c|c|}
\hline \multicolumn{4}{|c|}{ Tabela 02 - Matriz de Universidade Estadual (Univ. II) } \\
\hline Domínio Tecnológico & Domínio Estratégico & Domínio Científico & Domínio Acadêmico \\
\hline \multicolumn{4}{|c|}{ Disciplinas Obrigatórias } \\
\hline $\begin{array}{l}\text { Planejamento de } \\
\text { Sistemas de } \\
\text { Informação }\end{array}$ & $\begin{array}{l}\text { Métodos e Sistemas } \\
\text { Organizacionais }\end{array}$ & $\begin{array}{c}\text { Métodos e Técnicas } \\
\text { de Pesquisa em } \\
\text { Secretariado }\end{array}$ & Contabilidade Geral \\
\hline $\begin{array}{c}\text { Automação de } \\
\text { Escritórios }\end{array}$ & Técnicas Secretariais & & Língua Portuguesa \\
\hline $\begin{array}{l}\text { Gerenciamento de } \\
\text { Sistemas de } \\
\text { Informação }\end{array}$ & $\begin{array}{c}\text { Matemática } \\
\text { Comercial e } \\
\text { Financeira }\end{array}$ & & Língua Inglesa I \\
\hline \multirow[t]{2}{*}{$\begin{array}{c}\text { Sistemas de } \\
\text { Informações } \\
\text { Gerenciais }\end{array}$} & $\begin{array}{l}\text { Sistemas de } \\
\text { Administração }\end{array}$ & & Língua Espanhola I \\
\hline & $\begin{array}{c}\text { Organização de } \\
\text { Eventos }\end{array}$ & & $\begin{array}{c}\text { Técnicas de Redação } \\
\text { Comercial }\end{array}$ \\
\hline
\end{tabular}


Ubirajara Junior Gerardin, Aneridis Aparecida Monteiro \& Viviana Cristina Gianini

\begin{tabular}{|c|c|c|c|}
\hline & Gestão de Pessoas & & $\begin{array}{l}\text { Comunicação } \\
\text { Organizacional }\end{array}$ \\
\hline & $\begin{array}{c}\text { Comércio } \\
\text { Internacional }\end{array}$ & & $\begin{array}{c}\text { Psicologia das } \\
\text { Relações Humanas } \\
\text { no Trabalho }\end{array}$ \\
\hline & & & Língua Inglesa III \\
\hline & & & Língua Espanhola II \\
\hline & & & $\begin{array}{c}\text { Ética Empresarial e } \\
\text { Responsabilidade } \\
\text { Social }\end{array}$ \\
\hline & & & Economia Geral \\
\hline & & & Direito Empresarial \\
\hline $\begin{array}{c}\text { Estágio em } \\
\text { Secretariado } \\
\text { Executivo }\end{array}$ & $\begin{array}{c}\text { Estágio em } \\
\text { Secretariado } \\
\text { Executivo }\end{array}$ & $\begin{array}{c}\text { Estágio em } \\
\text { Secretariado } \\
\text { Executivo }\end{array}$ & $\begin{array}{c}\text { Estágio em } \\
\text { Secretariado } \\
\text { Executivo }\end{array}$ \\
\hline
\end{tabular}

Fonte: Elaborado pelos autores, 2010.

Org.: Ubirajara Gerardin Júnior, Aneridis Aparecida Monteiro e Viviana Cristina Gianini.

Tabela 03 - Matriz de Universidade Privada (Univ. III)

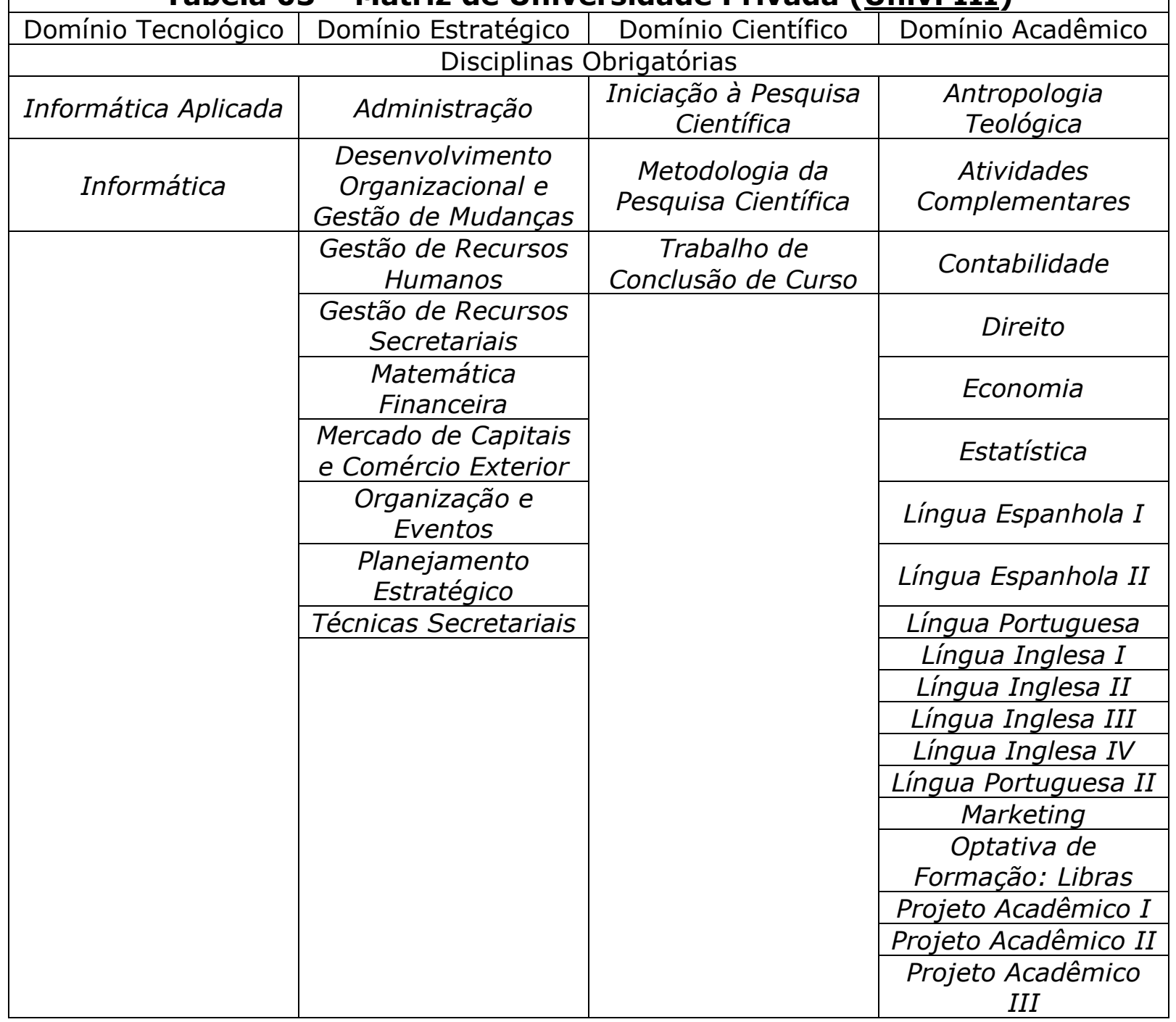

Revista de Gestão e Secretariado, São Paulo, v. 2, n. 2, p.58-78, jul./dez. 2011. 


\begin{tabular}{|c|c|c|c|}
\hline & & & $\begin{array}{c}\text { Psicologia } \\
\text { Organizacional } \\
\text { Redação e Expressão } \\
\text { Oral }\end{array}$ \\
\hline & & & Redação Empresarial \\
\hline & & & $\begin{array}{l}\text { Sociologia das } \\
\text { Organizações }\end{array}$ \\
\hline & & & Ética Profissional \\
\hline $\begin{array}{c}\text { Estágio } \\
\text { Supervisionado }\end{array}$ & $\begin{array}{c}\text { Estágio } \\
\text { Supervisionado }\end{array}$ & $\begin{array}{c}\text { Estágio } \\
\text { Supervisionado }\end{array}$ & $\begin{array}{c}\text { Estágio } \\
\text { Supervisionado }\end{array}$ \\
\hline
\end{tabular}

Fonte: Elaborado pelos autores, 2010.

Org.: Ubirajara Gerardin Júnior, Aneridis Aparecida Monteiro e Viviana Cristina Gianini. curricular.

As Univs. II e III não possuem disciplinas optativas em sua matriz

\section{MÉTOdOS E TÉCNICAS de PESQUISA}

No que se refere à pesquisa, Minayo apud Fabrizio (2010) defendem que é atividade da ciência o questionamento e a construção da realidade, sendo ela, a ciência, que fortalece a atividade de ensino e a atualiza frente à realidade do mundo.

Dessa forma, a pesquisa realizada classifica-se pela abordagem qualitativa. Quanto aos procedimentos técnicos pautou-se em análise bibliográfica a qual se embasa na revisão de literatura pertinente ao estudo, bem como análise documental do currículo do curso de graduação em Secretariado Executivo. Elas se restringem ao ementário de três universidades brasileiras de renome, sendo que duas delas de regime público, nos âmbitos federal e estadual e a outra de regime privado, porém com a mesma relevância e renome acadêmicos das públicas, no intuito de analisar, comparativamente, sua estrutura curricular, visando identificar as singularidades e diferenças entre elas e a forma como essas IES estão formando os futuros profissionais de Secretariado Executivo, bem como se estão adequadas às Diretrizes Curriculares estabelecidas pelo Ministério da Educação (MEC).

Para o alcance dessa proposta, utilizou-se os sítios eletrônicos das IES participantes da pesquisa como principal ferramenta de coleta de dados da Estrutura Curricular, bem como do Ministério da Educação no que concerne às Diretrizes Curriculares Nacionais para o curso de Secretariado Executivo, instituídas pela Resolução n. 3 de 2005 e Parecer CES/CNE nº. 0146/2002. 
Em complementação, foram revistos autores que têm estudado e fomentado as discussões e conceitos abrangentes do currículo, bem como a abordagem de seu campo, utilidade, finalidade e pesquisa, seguindo-se da reflexão desses conceitos para a formação do profissional de Secretariado Executivo, no sentido de auxiliar no combate de especulações errôneas acerca desse curso universitário e dessa área.

\section{APRESENTAÇÃo E ANÁLISE dOS RESULTADOS}

Observou-se em primeira instância o período de integralização dos cursos; aqui é possível comparar como as IES estão divididas na questão do tempo para a formação desse profissional.

Dentro do que é estabelecido pela Resolução no. 2/2007, as três instituições analisadas estão de acordo a este item, uma vez que a referida resolução determina que a carga horária mínima para integralização do Curso de Secretariado Executivo seja de 2400 horas, bem como no período de 3 ou 4 anos; é interessante ressaltar também que a proposta de carga horária das IES analisadas respeitam o desenvolvimento das atividades e da maturidade dos acadêmicos do curso.

Em segunda instância nota-se a quantidade de disciplinas dispostas em cada uma das Instituições; aquela que foi elencada na Tabela 01 possui o maior número de disciplinas ofertadas aos acadêmicos, levando-se em consideração as obrigatórias e optativas.

Pode-se observar também que as Tabelas 01 e 02, as quais trazem a matriz curricular das universidades de regime público oferecem maior tempo de integralização de curso do que a universidade de regime privado, abordada pela Tabela 03.

Já em terceira instância com o agrupamento realizado de acordo com a análise conteudista das disciplinas, notou-se que as universidades pesquisadas focam seus esforços no desenvolvimento de conteúdos acadêmicos das disciplinas de seu currículo, ou seja, na delas. A disciplina de Estágio Supervisionado, porém, foi citada nos quatro domínios, tendo em vista seu papel que está diretamente ligado na atuação profissional do discente, levando a teoria 
aprendida à práxis.

Por outro lado, é interessante ressaltar o esforço das universidades pesquisadas em alavancar o curso de secretariado executivo, bem como a produção científica da área, cuja preocupação é comprovada nas disciplinas de Monografia, TCC (Trabalhos de Conclusão de Curso) e outras correlatas, uma vez que as DCNs não fazem essa exigência ao curso.

Com essa análise comparativa pode-se notar que as IES estão preocupadas com uma formação consistente de seus acadêmicos, levando-se em consideração que por suas diversas disciplinas, as quais muitas se aliam a outras áreas do conhecimento, oferecem ao aluno uma formação abrangente e pluralista, capaz de torná-los aptos a ingressarem no mercado de trabalho com os quatro domínios citados pelas autoras Santos e Caimi (2009), científico, acadêmico, tecnológico e estratégico.

Assim, percebe-se que o curso de graduação em Secretariado Executivo oferece ao acadêmico a formação adequada frente às diversidades do mercado de trabalho, bem como suas complexidades.

\section{CONSIDERAÇÕES FINAIS}

Ao observar a importância do tema para a área, é possível discorrer sobre a formação acadêmica do profissional de Secretariado Executivo, bem como as diversas áreas que ele tem domínio, quebrando o paradigma que remete o curso universitário a uma simples formação tecnicista.

Dessa forma podemos observar que a formação desse profissional encaixa-se nas exigências estabelecidas pelos estatutos e legislações pertinentes, bem como na exigência do mercado de trabalho. Neste sentido observou-se consonância entre a normatização das Diretrizes, a concepção dos estudiosos da área e a realidade abordada na pesquisa que incluiu três instituições de ensino superior brasileiras com o referido curso.

Vale enfatizar que as organizações buscam um profissional multidirecional, capaz de realizar multifunções; assim o secretário está apto a exercê-las eticamente dentro dos padrões da Instituição, tendo em vista sua formação pluralista demonstrada na Estrutura Curricular das IES. 
Assim, o objetivo desse trabalho foi o de evidenciar a amplitude da formação universitária do Curso de Graduação em Secretariado Executivo, embasando-se na discussão e reflexão do currículo de um modo geral, bem como na abordagem das singularidades dos currículos dos cursos e sua relevância frente às questões de mercado de trabalho e científicas.

Pode-se considerar no decorrer da pesquisa que as IES se preocupam com a formação do profissional de Secretariado Executivo, tendo em vista que respeitam as Diretrizes Curriculares Nacionais estabelecidas pelo MEC, bem como incentivam a produção científica dos acadêmicos, através dos TCCs, demonstrando de certa forma que o currículo desses cursos também se preocupa com o retorno que os futuros profissionais trarão à sociedade de um modo geral.

Este trabalho é apenas o início de um assunto que pode ser pesquisado mais minuciosamente com o objetivo de auxiliar ainda mais a reflexão acerca do Currículo e do Curso de Graduação em Secretariado Executivo, uma vez que ele, o profissional secretário, ocupa lugar de destaque nos segmentos em que atua.

\section{REFERÊNCIAS}

BÍSCOLI, Fabiana Regina Veloso e CIELO, Ivanete Daga. Gestão organizacional e o papel do secretário executivo. Toledo: Universidade Estadual do Oeste do Paraná. vol. 3 n. 3. 2004.

BRASIL. Ministério da Educação. Resolução n. 3 de 23 de junho de 2005. Institui as diretrizes curriculares para o curso de graduação em secretariado executivo. Brasília, DF, 2005. Disponível em <http://www.ufv.br/seg/diretrizes/sec.pdf>. Acesso em: 4 de fevereiro de 2011.

BRASIL. Ministério da Educação. Resolução n. 2 de 18 de junho de 2007. Dispõe sobre carga horária mínima e procedimentos relativos à integralização e duração dos cursos de graduação, bacharelados, na modalidade presencial. Brasília, DF, 
2007. Disponível em <http://nova.fau.ufrj.br/uploads/64-teste.pdf>. Acesso em: 19 de fevereiro de 2012.

COSTA, Marisa Vorraber. (Org.) O currículo nos limiares do contemporâneo. 4. ed. Rio de Janeiro: DP\&A, 2005.

DURANTE, Daniela Giareta e FÁVERO, Altair Alberto. (Orgs.) Gestão secretarial: formação e atuação profissional. Passo Fundo: Ed. Universidade de Passo Fundo, 2009.

FABRIZIO, Silvane Brand e PEGORINI, Diana Gurgel. O papel do secretário executivo no contexto das organizações pós-modernas. Artigo (Especialização em Secretariado Executivo) - Faculdade de Tecnologia Internacional. 2010

GARCIA. Regina Leite e MOREIRA, Antonio Flavio Barbosa. (Orgs.) Currículo na contemporaneidade: incertezas e desafios. Tradução de Silvana Cabucci Leite, Beth Honorato e Dinah de Abreu Azevedo. São Paulo: Cortez, 2003.

MACEDO, Roberto Sidnei. Currículo - campo, conceito e pesquisa. 1. ed. Petrópolis: Vozes, 2007.

NONATO JÚNIOR, Raimundo. Epistemologia e teoria do conhecimento em secretariado executivo: a fundação das ciências da assessoria. Fortaleza: Expressão Gráfica, 2009.

REVISTA PRO-POSIÇÕES. Campinas. Faculdade de Educação da Unicamp. vol. 18 , n. 2 (53), maio/ago. 2007.

SABINO, Rosimeri Ferraz e MARCHELLI, Paulo Sérgio. O debate teóricometodológico no campo do secretariado: pluralismos e singularidades. Cadernos EBAPE. BR, vol. 7, no 4, Rio de Janeiro, dez. 2009.

SEVERINO, Antonio Joaquim. Metodologia do trabalho científico. 23 ed., ver. e aum., São Paulo: Cortez, 2007. 
ZABALA, Antoni. Enfoque globalizador e pensamento complexo: uma proposta para o currículo escolar. Tradução de Ernani Rosa. Porto Alegre: ArtMed, 2002.

Data do recebimento do artigo: 04/08/2011

Data do aceite de publicação: 02/11/2011

Revista de Gestão e Secretariado, São Paulo, v. 2, n. 2, p.58-78, jul./dez. 2011. 